\title{
CONCRETE SLAB REINFORCED WITH GFRP AND EXTERNALY STRENGTH WITH CARBON SHEET UNDER IMPACT LOAD
}

${ }^{\star} E m a n$ H. Hamza ${ }^{1}$

Mutaz K. Madlum 1

\begin{abstract}
When FRP bars used in concrete structures that exposed to harsh environments, their service life extended and the cost of their life cycle reduced. Recently, methods of externally bonding Carbon Fiber Reinforced Polymer (CFRP) sheets to RC slabs proposed to improve the dynamic behavior of RC slabs under impact load. In this study, the effect of the number of CFRP sheet layers (one or two) and the arrangement of CFRP sheets (covering the whole or parts of the surface) on the dynamic behavior of slabs reinforced with GFRP bar investigated. Nine specimens of $(1550 \times 1550 \times 150) \mathrm{mm}$ reinforced by GFRP bars were tested. A single control specimen was unstrings and eight specimens were strength with CFRP sheet on the tension face. A rigid steel projectile used to apply two dropping-weights of $150 \mathrm{~kg}$ as an impact load. The height of the drop was 5 meters. To determine punching shear capacity and critical velocity of perforation, different codes used and compared with the experimental results. The results of the experiments revealed that slab shear properties have a significant impact on their general behavior. Strength slab with carbon sheet enhances the behavior of RC slabs under impact loads and increases shear punching capacity.
\end{abstract}

Keywords: RC slabs, punching shear, critical velocity, dynamic performance, GFRP reinforcement, carbon sheet, punching shear, dynamic performance.

\section{Introduction}

Concrete frequently used to protect structural parts from explosions and impact loads. In addition to military applications, the nuclear sector is particularly concerned about the impact resistance of concrete structures. Different missile threats, such as fragments produced by transverse explosions, plane accidents, and other occurrences. These missiles might have a wide range of shapes, sizes, impact velocities, deforming rigidities, and hardness resulting in a wide damage spectrum on the target. Most design equations on the other hand simplify missiles into hard axisymmetric projectiles because they use the normal product to maximize local impact damage [1].

The majority of current methods for designing concrete buildings under impact depend on empirical equations and full-scale tests. Impacts and impulsive loadings are often extreme loading scenarios with a very low likelihood of occurring over a structure's lifespan [2].Various empirical equations have been established since in the early twentieth century to estimate penetration depth and prevent scabbing or perforation in RC panels affected by deformable or non-deformable projectiles [3].

The majority of these formulas were created based on experimental data and considered a limited range of projectile mass, velocity, and concrete strength.

They didn't evaluate the reinforcement's effect on the impact resistance of reinforced concrete panels.

*Corresponding Author: emanhibtallah2006@gmail.com 
The role of reinforcement in RC panel impact resistance was investigated by Alkloub research [4]. The following are some of the formulas that are commonly used to determine local projectile effects and minimal target thicknesses in order to avoid perforation and scabbing:

Petry developed his original penetration depth formula in 1910, which was later modified and dubbed Modified Petry I [5]. The penetration depth is calculated using the following formula:

$x=k \frac{M}{d^{3}} \log \left(1+\frac{V^{2}}{19974}\right)$

The coefficient $(\mathrm{K})$ has value equal to 0.000636 for unreinforced concrete panels, and equal to $0.000339,0.000226$ for normally and heavily reinforced concrete panels respectively.the strength of the concrete does not account in this formula. U.S. Army Corps of Engineers (ACE) [6] developed a penetration formula in 1946, based upon the statistical fitting of experimental data which has been tested by other researchers (ACE, 1946). The ACE penetration depth formula is given as:

$\frac{x}{d}=\frac{0.00035}{\sqrt{f c^{\prime}}}\left(\frac{M}{d^{3}}\right) d^{0.215} V^{1.5}+0.5$

In 1946 National Defense Research Committee (NDRC) [7] proposed a model called "Theory of Penetration" to estimate the penetration depth for a projectile hitting a finite thickness target (NDRC, 1946). The following is the NDRC formula for penetration:

$x=\left[4 K N M\left(\frac{V}{1000 D}\right)^{1.8}\right]^{0.5}$ for $\frac{X}{d} \leq 2.0$

$x=\left[K N M\left(\frac{V}{1000 D}\right)^{1.8}+d\right]$ for $\frac{X}{d} \geq 2.0$

Where: $\mathrm{K}$ is equal to $180 / \sqrt{f c^{\prime}}, \mathrm{N}$ is the projectile shape factor $=0.72$ for the flat-nosed projectile, and equal to 1.0 for the sphericalnosed projectile, and to 0.84 and 1.14 for blunt- nosed projectile and very sharp-nosed projectile respectively.

Nuclear power plants are still used the NDRC formulas in the design to resist impact. The U.S. ACE enhanced NDRC equation for perforation in order to cover a wider range and to consider the infinite thickness of the target which became the modified NDRC formulas [8]. The modified formula of the NDRC for perforation thickness is:

$$
\begin{aligned}
& \text { for } \frac{x}{d} \leq 1.35 \text { or } \frac{h_{p}}{d} \leq 3 \\
& \frac{h_{p}}{d}=3.19\left(\frac{X}{d}\right)-0.718\left(\frac{X}{d}\right)^{2} \\
& \text { for } 1.35 \leq \frac{X}{d} \leq 13.5 \text { or } 3 \leq \frac{h p}{d} \leq 18 \\
& \frac{h_{p}}{d}=1.32+1.24\left(\frac{X}{d}\right)
\end{aligned}
$$

Calculate the critical perforation velocity as well. In 1974, EDF and CEA (French Alternative Energies and Atomic Energy Commission) in France began developing a reliable formula for predicting the behavior of concrete structures in the face of a missile's ballistic force. They proposed a perforation limit formula that based on sets of air gun and drop-weight tests.CEB (1988) [9] established an impact velocity limit based on the experimental scabbing limit to avoid scabbing. It has also calculated the critical perforation impact velocity and this calculation based on data from experiments. A comparison of the real impact and critical velocities must be made between the real impact and the critical velocities must been made.

$V p=1.3 \rho^{1 / 6} f c^{1 / 2}\left(\frac{d e^{2}}{M}\right)$

Then, Fullard et al. (1991) [10] modified the CEA-EDF equation for taking under consideration the quantity of the reinforcement with $r$ reinforcement percentage which is 
characterized by the percentage every way in every face.

$$
\begin{aligned}
& V p=1.3 w^{1 / 6} f c^{1 / 2}\left(\frac{d_{p} H^{2}}{M}\right)(r+0.3)^{2 / 3} \\
& \cdots \cdot \cdot \cdot \cdot \cdot \text {. } \\
& \cdots \cdot \cdot \cdot \cdot \cdot \\
& r=\frac{A b}{H S}+\frac{n w t_{f}}{b d}\left(\frac{E_{s f}}{E_{f}}\right)
\end{aligned}
$$

Berriaud et al. (1983) [11] improved the formula by taking into account concrete strength, reinforcement ratio, and projectile nose as shown below:

$v_{p}^{2}=Z\left[0.35\left(\frac{M_{a}}{M_{a o}}\right)^{\gamma}+0.65\right]^{2}\left(\frac{f c^{\prime}}{f c o^{\prime}}\right)^{-\frac{1}{2}}$

$Z=1.89 \rho^{1 / 3} f c^{\prime}\left(\frac{d e^{2}}{M}\right)^{\frac{4}{3}} N^{2}$

Where: $\mathrm{Mao}=200 \mathrm{~kg} \cdot \mathrm{m}^{-3}$ reference steel reinforcement density represents the number of steel layers functions which equal 0.70 for two steel layers and 0.10 for four layers of steel, $f_{c o}=36 \mathrm{MPa}$ concrete reference compressive strength, and $\mathrm{N}$ represents the nose geometry function which equal 1 for the flat nose and 1.18 for the hemisphere one.

Multiday [12] discovered that the critical velocity of perforation for all high-strength concrete slabs could be calculated accurately using the CEB code expression (1988). However, the case of normal strength concrete in a fixed end condition, the test result showed a critical velocity reached to $30 \%$ higher than the code expected. On other hand, the test result was about $4 \%$ lower than the code account for simply supported conditions. In general, the CEB (1988) code prediction could used to calculate the critical impact velocity with accuracy especially for high-strength concrete panels. Buzaud et al. [13] compared empirical formulae (8) and (9) to common database containing 151 perforation tests. While EDF-CEA equation (9) provides a significant advantage in terms of accuracy, its application range does not include new concrete with ultra-high performance. Furthermore, they discovered that no tested formula accounts for share reinforcement effect. The specimens' punching shear capacity also represented in this study. Punching shear capacity of flat slabs reinforced with steel, CFRP, and GFRP bars studied experimentally and analytically. The results of some of the studies summarized in the following section:

Nguyen-Minh and Rovnak [14] studied punching shear behavior of concrete two-way slabs reinforced with GFRP bars. Six interior GFRP and steel-reinforced slab-column connections tested on a large scale with a column dimension of (200 x 200) mm, the slab-column connections measured $(2200 \times 2200 \times 150) \mathrm{mm}$. Three of the six connections reinforced with GFRP bars, while the other three reinforced with steel bars. The flexural reinforcement ratios in the slabs ranged from 0.4 to 0.8 percent, with no compression reinforcement used in any of them. All slabs tested with concentrated load acting on the column stub in the middle of each slab, which simply supported on all four sides. According to the findings increasing, the GFRP reinforcement ratio resulted in a 36 percent increase in punching strength and a nearly 35 percent reduction in deflection.

El-Ghandour et al. [15] investigated the punching shear behavior of two-way GFRP reinforced slabs with and without GFRP shear reinforcement. The researchers tested eight $(2.0$ $\mathrm{x}$ 2.0) $\mathrm{m}$ square simply supported specimens in a two-phase experimental program, with a (200x200) mm square column, all specimens were $175 \mathrm{~mm}$ thick. All specimens subjected to a concentrated load in the slabs' center. Four 
specimens tested in the first phase, two slabs reinforced with GFRP bars $(0.18 \%)$, and other two slabs reinforced with CFRP bars $(0.15 \%)$. The flexural reinforcement ratio increased to 0.38 percent in the second phase and the specimens failed in the first phase due to bond slip of the flexural bars at loads less than their expected flexural and punching shear capacities due to a low reinforcement ratio and wide spacing between reinforcement bars.

Esfahani et al. [16] investigated the punching shear strength of flat slabs reinforced with CFRP sheets installed on the slab's tension side. Discovered that using of CFRP sheets as flexural reinforcement, in addition to steel reinforcing bars could improve slab punching shear strength.

Metwally [17] tested the punching shear strength of reinforced concrete flat slabs with various types of FRP bars. The punching shear strengths in the experiments compared to theoretical predictions and a number of existing models and two methods for predicting the punching shear strength of FRP-reinforced slabs proposed by the author.

In Jae-Ick Jang \& Su-Min Kan [18] study, the effects of flexural reinforcement and shear reinforcement on the punching shear strength of slab-column connections and analyzed in this study. Six slab-column connection specimens constructed with varying flexural reinforcement and shear reinforcement then subjected to gravity load tests. Experimental results showed that all specimens destroyed by punching failure and slab-column connection behaved differently depending on the amount of shear reinforcement and flexural reinforcement.

Mink wan Ju et al. [19] investigated the punching shear behavior of full-scale two-way concrete slabs reinforced with glass fiber reinforced polymer (GFRP) bars. Four full-scale two-way concrete slabs fabricated with two supporting RC beam girders reinforced with steel reinforcements. At $2400 \mathrm{mmwide}$ and $3000 \mathrm{mmlong}$ and considered thickness of 220 mm satisfies the minimum depth calculated by using the formula of $1.2(S+3000) / 30$ where $S$ is the center-to-center spacing of the supports. The recommended clear cover of the concrete bridge deck was $25.4 \mathrm{~mm}$. However, in this study the average of the test results demonstrated that the two-way concrete slabs with GFRP bars satisfied the allowable deflection and crack width under the service load specified by the design specification even in the state of the minimum reinforcement ratio.

\section{Concrete Mixes}

The mix proportion to produce concrete (cement sand: crushed coarse aggregate) was (1: 2.175: $2.625)$ by weight, and the water-cement ratio was (0.225). Table1. Showed the mix contents for (1) $\mathrm{m}^{3}$ of concrete.

Table 1. Mix proportions for (1) $\mathrm{m}^{3}$ of concrete

\begin{tabular}{ccccc}
\hline $\begin{array}{c}\text { Cement } \\
\left(\mathrm{kg} / \mathrm{m}^{3}\right)\end{array}$ & $\begin{array}{c}\text { Sand } \\
\left(\mathrm{kg} / \mathrm{m}^{3}\right)\end{array}$ & $\begin{array}{c}\text { Gravel } \\
\left(\mathrm{kg} / \mathrm{m}^{3}\right)\end{array}$ & $\begin{array}{c}\text { Admixtu } \\
\text { re } \\
\left(\mathrm{ml} / \mathrm{m}^{3}\right)\end{array}$ & W/C \\
\hline 400 & 870 & 1050 & 3500 & 0.22 \\
\hline
\end{tabular}

\section{Casting and Compaction}

Firstly, all the molds well cleaned their inner surfaces slightly oiled to prevent the adhesion of concrete to the molds. Then put the Glass Fiber Reinforcement and fixed the strain gage in its position with glue, and covered it with tape. Then poured concrete mixture (ready mixed concrete) into the mixer and compact it by using a mechanical vibrator (rod vibration) to gain more uniformity. Then leveled the top of the surface of each specimen and smoothed it with a steel trowel, as shown in Figure 1. 


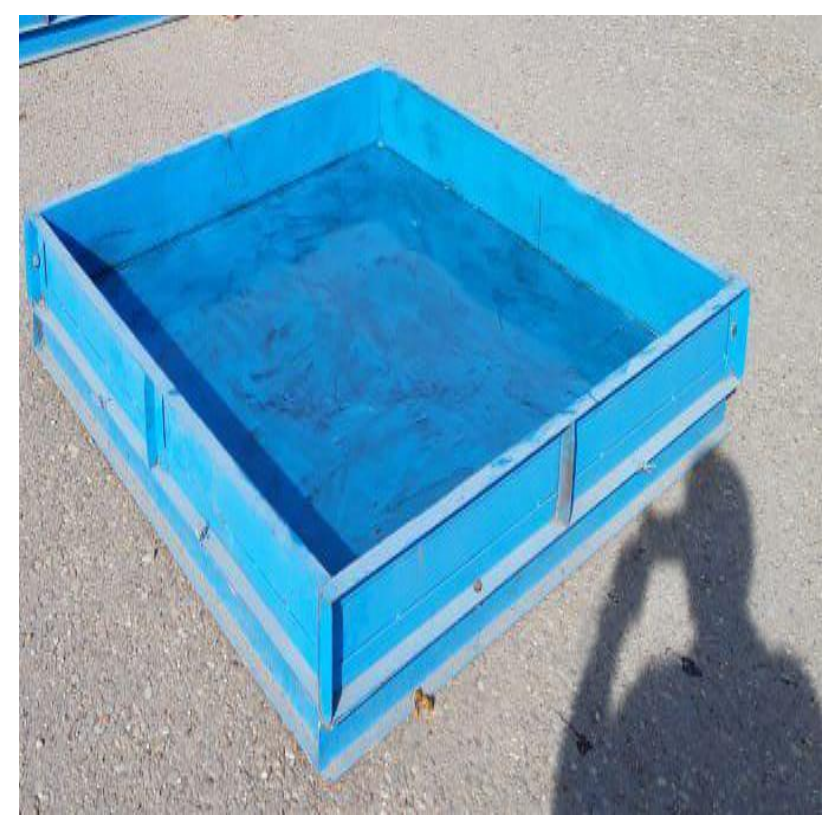

(a)

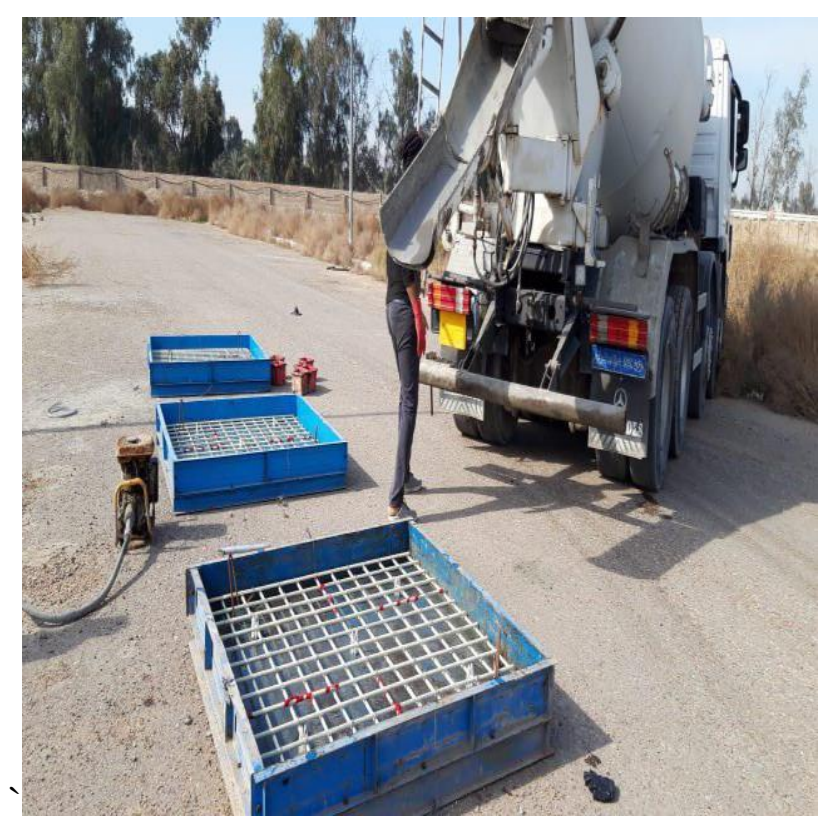

(b)

Figure 1. Stage of prepare slab: (a) Mold of test specimen (b) Casting of test specimen

\section{Test Specimens}

Nine slabs of reinforced concrete poured as shown in Figure2. The tested slabs have dimensions of $(1550 \times 1550 \times 150) \mathrm{mm}$ with a 25 $\mathrm{mm}$ clear cover. Furthermore, all raw materials for concrete including fine aggregates, coarse aggregates, and cement are prepared in accordance with the Iraqi specifications. Table 2 Table 3. In addition, Table 4. List the properties of GFRP, CFRP, and resin respectively. The details of the tested slab shown in Table 5.The number of CFRP sheet layers (one or two) and the arrangement of CFRP sheets (covering the whole or parts of the surface, as well as the number and width of stripes) are the parameters of the structural test for slabs.

Table 2. Properties of GFRP reinforcement*

\begin{tabular}{lcccc}
\hline $\begin{array}{l}\text { Type } \\
\text { NO. }\end{array}$ & $\begin{array}{c}\text { Dia } \\
.(\mathrm{mm})\end{array}$ & $\begin{array}{c}\text { Area } \\
\left(\mathrm{mm}^{2}\right)\end{array}$ & $\begin{array}{c}\mathrm{E} \\
(\mathrm{GPa})\end{array}$ & $\begin{array}{c}\mathrm{E}_{\mathrm{fu}} \\
(\mathrm{MPa})\end{array}$ \\
\hline B100-13 & 13 & 126.7 & 46 & 758 \\
\hline
\end{tabular}

* According to the manufacture company

Table 3. Properties of CFRP sheet

\begin{tabular}{lc}
\hline Thickness $(\mathrm{mm})$ & 0.167 \\
Tensile strength $(\mathrm{MPa})$ & 4000 \\
Elastic modulus $(\mathrm{MPa})$ & 230000 \\
Ultimate tensile strain $(\%)$ & 1.7 \\
Density $\left(\mathrm{g} / \mathrm{cm}^{3}\right)$ & 1.82
\end{tabular}

Table 4. Properties of resin remarks of resin*

\begin{tabular}{ll}
\hline Adhesive type & $\begin{array}{l}\text { Impregnating epoxy resin } \\
\text { Part A (resin) : part B } \\
\text { (hardener) } 4: 1 \text { by } \\
\text { weight }\end{array}$ \\
Mixing ratio & 30 \\
Tensile strength $(\mathrm{MPa})$ & 3800 \\
Elastic modulus $(\mathrm{MPa})$ & 1.31 \\
$\begin{array}{l}\text { Density (kg/lt) } \\
* \text { According to the manufacture company }\end{array}$ \\
\hline
\end{tabular}

Table 5. Specimens' details

\begin{tabular}{cccccc}
\hline $\begin{array}{c}\text { Slab } \\
\text { symbol }\end{array}$ & $\begin{array}{c}\text { Type } \\
\text { of } \\
\text { rebar }\end{array}$ & $\begin{array}{c}\text { Thick } \\
(\mathrm{mm})\end{array}$ & $\begin{array}{c}(\rho \mathrm{b}) \\
\%\end{array}$ & $(\rho) \%$ & $\mathrm{~S}(\mathrm{~mm})$ \\
\hline $\begin{array}{c}\text { All test } \\
\text { slabs }\end{array}$ & GFRP & 150 & 0.672 & 0.851 & $\varnothing 13 @ 125$ \\
\hline
\end{tabular}




\section{Mechanical Properties}

The mechanical characteristics of concrete can have summarized in the Table 6 .

Table 6. The mechanical characteristics of the tested specimens

\begin{tabular}{|c|c|c|c|c|c|}
\hline Slab name & $\begin{array}{c}f_{c u} \\
\text { (Mpa) }\end{array}$ & $\begin{array}{c}f_{c}^{\prime} \\
(\mathrm{Mpa})\end{array}$ & $\begin{array}{c}f_{t} \\
\text { (Mpa) }\end{array}$ & $\begin{array}{c}f_{r} \\
(\mathrm{Mpa})\end{array}$ & $\begin{array}{c}\mathrm{Ec} \\
(\mathrm{Mpa})\end{array}$ \\
\hline $\begin{array}{l}\mathrm{SG}, \mathrm{SGC}_{1^{-}} \\
\mathrm{B}_{1}, \mathrm{SGC}_{2^{-}} \\
\mathrm{B}_{1}\end{array}$ & 41.32 & 31.4 & 4.57 & 6.32 & $\begin{array}{c}26336 . \\
78\end{array}$ \\
\hline $\begin{array}{l}\mathrm{SGC}_{3^{-}} \\
\mathrm{B}_{2}, \mathrm{SGC}_{4^{-}} \\
\mathrm{B}_{1}, \mathrm{SGC}_{5^{-}} \\
\mathrm{B}_{1}\end{array}$ & 40.21 & 30.96 & 4.34 & 6.12 & $\begin{array}{c}26151 . \\
6\end{array}$ \\
\hline $\begin{array}{l}\mathrm{SGC}_{6^{-}} \\
\mathrm{B}_{2}, \mathrm{SGC}_{7^{-}} \\
\mathrm{B}_{1}, \mathrm{SGC}_{8^{-}} \\
\mathrm{B}_{1}\end{array}$ & 43.11 & 32.76 & 4.8 & 6 & $\begin{array}{c}26901 . \\
1\end{array}$ \\
\hline
\end{tabular}

\section{Prepare Slab}

The impact induced by drop weight performed on nine slabs with dimensions of (1550x 1550x 150) $\mathrm{mm}$ reinforced with GFRP bar as show Figure 2. One RC slab without strength and eight slabs strength with externally bonded CFRP sheets to investigate the impact load behavior of RC slabs. As shown in Figure 3. In all RC slabs, a single layer of GFRP of $13 \mathrm{~mm}$ diameter with $125 \mathrm{~mm}$ spacing located in the tension zone at $25 \mathrm{~mm}$ above the bottom surface of the slabs used. The control slab was designated by the slab symbols (SG), where (S) refers to the slab and $(\mathrm{G})$ refers to the slab reinforced with GFRP bar. The slab symbols (SG): (S) refers to a slab and $(\mathrm{G})$ refers to a slab reinforced with GFRP bar and the control slab, while (SGCn-Bm) refers to slabs reinforced with GFRP bar and strengthened with CFRP sheet on the bottom surface. Which (n) refers to the number of samples and $(\mathrm{m})$ refers to the number of layers. The diameter of the GFRP bar and the clear cover could used to calculate the average effective depth of all specimens and the effective depth averages $118.5 \mathrm{~mm}$. Parameters such as the number of CFRP sheet layers used to investigate the behavior of RC slabs reinforced with CFRP sheets. (One or two), the covering area of CFRP sheets (covering the whole surface or covering parts of the surface by area).

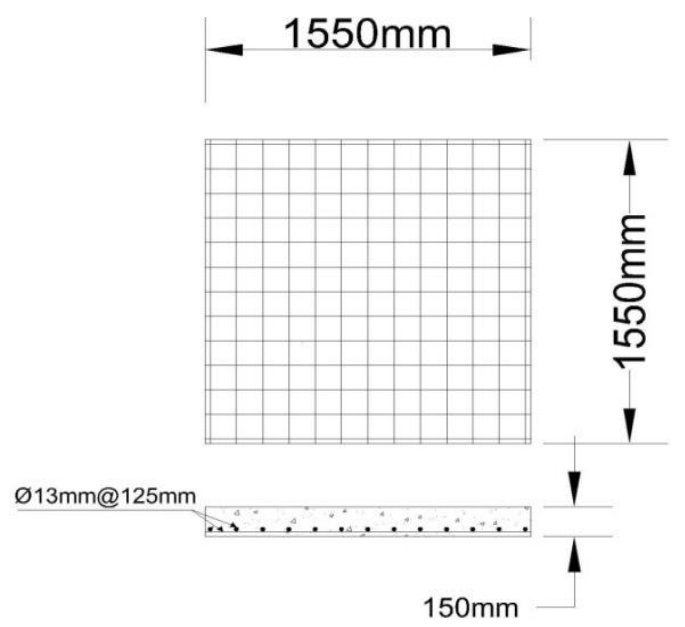

Figure 2. Test specimens (all dimensions in $\mathrm{mm}$ )
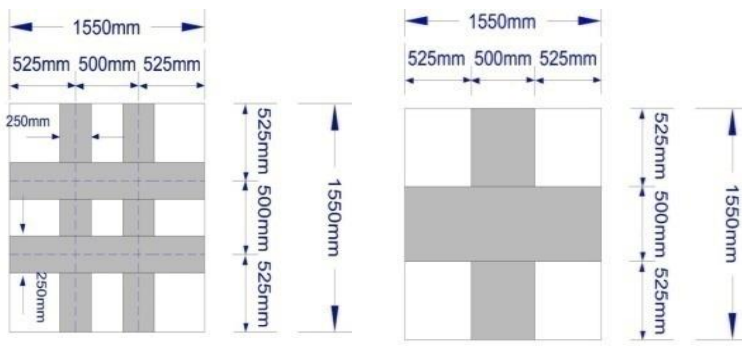

$\mathrm{SGC}_{1}-\mathrm{B}_{1}$

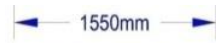

$525 \mathrm{~mm} 500 \mathrm{~mm} 525 \mathrm{~mm}$

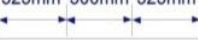

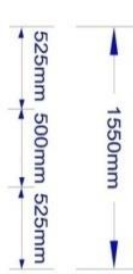

$\mathrm{SGC}_{2}-\mathrm{B}_{1}$ and $\mathrm{SGC}_{3}-\mathrm{B}_{2}$

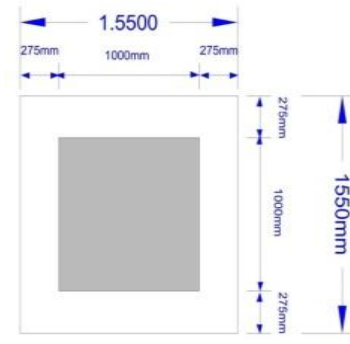

$\mathrm{SGC}_{4}-\mathrm{B}_{1}$

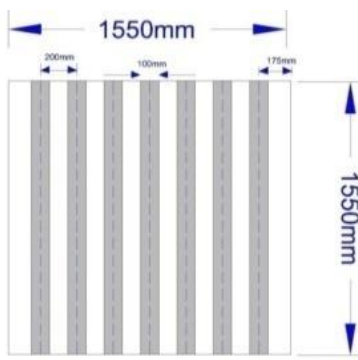

$\mathrm{SGC}_{7}-\mathrm{B}_{1}$

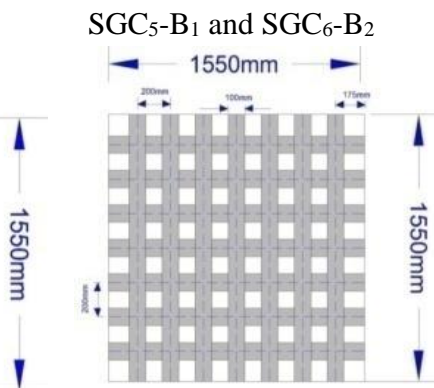

$\mathrm{SGC}_{8}-\mathrm{B}_{1}$

Figure 3. Details of strength layout for slab specimens 


\section{Test Setup}

The slabs tested at Mustansiriyah University, College of Engineering. The drop-mass low velocity impact setup designed specifically for these tests. All specimen slabs had the same loading and supporting conditions. Specimens simply supported on all four corners and subjected to impact in the middle. The slab bolted to the underlying support on all four corners with four $16 \mathrm{~mm}$ bolts diameter. To avoid any rebounding due to impact load, and then the stand that carried the specimen bolted to the earth with a $20 \mathrm{~mm}$ bolt diameter to avoid any movement during the test two and sometimes three impact drops of $150 \mathrm{~kg}$ weight are applied to each specimen from a constant height of 5 until a crack appears. SG failed at the first drop, while $\mathrm{SGC}_{6-}$ $\mathrm{B}_{2}$, SGC3- $\mathrm{B}_{2}$ failed at the third drop and all remaining test slabs failed at the second blow. The impact force excited by the falling steel weight found by second law of Newton using the average reading of two (10000g and 5000g) accelerometers mounted to the drop-weight.

\section{Result and Discussion}

\subsection{Midpoint Displacement Data}

Figure 4. Show a comparison of RC slabs that strengthened overall by CFRP sheets to compare the results in terms of the number of CFRP layers and their width. A significant difference in maximum deflections between all strength specimens and the reference slab (SG) observed. Only the spaceman (SG) failed at the first blow, with high scabbing and penetration, while all the strong slabs failed at the second and third blows. This improvement could attribute to the high strength of the CFRP sheet in the specimen's initial stiffness. However, due to accumulated energy, the second strike caused stress concentration on the backside, resulting in large maximum deflections. When compared the results of second and first blow with respect to the number of CFRP layers show that the increasing of CFRP sheet layer at bottom of slab from one layer to two layers leads to a peak displacement reduction of $12 \%$ from (42)mm to (37)mm and $7.7 \%$ from (39)mm to (36)mm respectively. When comparing the maximum displacement of distributed narrow longitudinal GFRP strips to broad CFRP strips, it is obvious that the use of distributed narrow longitudinal GFRP strips minimizes the maximum displacement more than wide CFRP strips. The greatest displacement was at the second blow, for a slab with seven $100 \mathrm{~mm}$-wide layers. The slab with four layers of $250 \mathrm{~mm}$-wide GFRP strips ( $\left.\mathrm{SGC}_{1}-\mathrm{B}_{1}\right)$ had a maximum displacement of (44) $\mathrm{mm}$, indicating that the distributed CFRP strips are more economical. When compared maximum displacement of the second impact for slabs strengthened by CFRP with respect to their area ranges from (0.25 to 1$) \mathrm{m} 2$. $\mathrm{SGC}_{4}-\mathrm{B}_{1}$ and $\mathrm{SGC}_{5}$ $\mathrm{B}_{1}$ lead to a displacement reduction of $9.3 \%$ and when comparing the strength slabs with nonstrength slabs found a large difference between them. Because the displacement of the nonstrength slab which failed at the first blow was (46) $\mathrm{mm}$ and the higher displacement of the strength slab at the first blow was (15) $\mathrm{mm}$ at slab $\mathrm{SGC}_{1}-\mathrm{B}_{1}$. Observed that used this strengthening method has a significant impact on decreasing the maximum displacement of slabs.

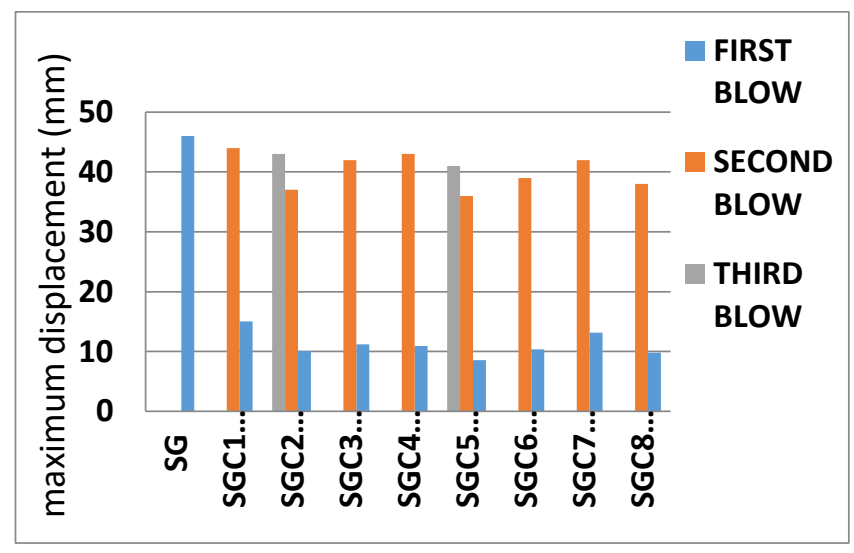

Figure 4. Maximum midpoint displacement 


\subsection{Critical Velocity for Perforation}

Based on equations ( $8 \& 10)$, values relating to critical perforation velocity can be determined:

$V_{p}=1.3 w^{1 / 6} f c^{1 / 2}\left(\frac{d_{p} H^{2}}{M}\right)^{2 / 3}(r+0.3)^{2 / 3}$

$V_{p}=\sqrt{2 g h}$

$\mathrm{w}=$ concrete density $\left(2500 \mathrm{~kg} / \mathrm{m}^{3}\right), \mathrm{fc}^{\prime}=$ cylinder compressive strength, $\mathrm{d}=$ missile perimeter (200mm), M = missile mass $(150 \mathrm{~kg}), \mathrm{r}=$ sum of percentage of reinforcements and ratio of carbon sheet, $\mathrm{g}=$ acceleration $\left(9.81 \mathrm{~m} / \mathrm{sec}^{2}\right), \mathrm{h}=$ height of dropped mass, $\mathrm{H}=$ thickness of the concrete slab. The critical velocity obtained by equation (8) (CEA - EDF code) was compared to the velocity predicted by equation (10) as shown in Figure 5. This based on the potential energy being equal to the kinetic energy Table 7 . Shows that the critical velocity of perforation based on CEB (1988) for $\left(\mathrm{SGC}_{1}-\mathrm{B}_{1}, \mathrm{SGC}_{2}-\mathrm{B}_{1}\right)$ specimens was very close to the result of the velocity for $\mathrm{SG}$ specimens. As a result, the control parameter that affects the critical velocity is slab compressive strength. The velocity obtained by equation (8) on the other hand is roughly $24 \%$ higher than the velocity determined by equation (10) for the tested specimen with compressive strength equal to $32.76 \mathrm{MPa}$. When the specimens with a compressive strength of $30.96 \mathrm{Mpa}$ were compared the velocity (CEB prediction) was found to be $22 \%$ and $19 \%$ higher than the velocity calculated by equation (10) and $21 \%$ higher when the compressive strength was $31.4 \mathrm{MPa}$. In conclusion, the prediction of critical velocity based on the CEB (1988) equation (8) is adequate and could used to estimate the critical velocity of a concrete slab subjected to impact loading because the formula includes the parameters of thickness, reinforcement ratio, and compressive strength.

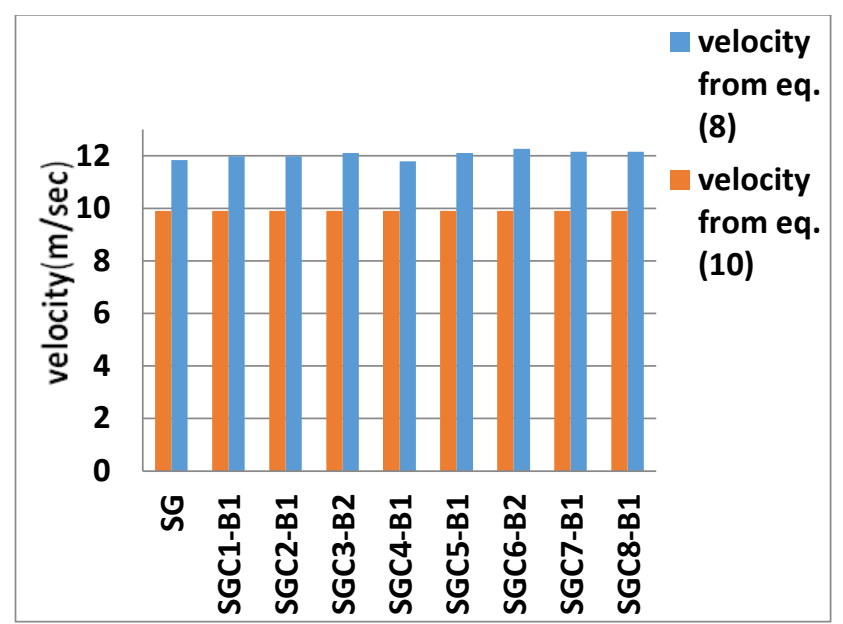

Figure 5. Critical velocity of perforation

Table 7. Calculation of critical velocity

\begin{tabular}{ccccc}
\hline Specimen & $\mathrm{r} \%$ & $\begin{array}{c}\mathrm{V} \\
\text { eq.(8) } \\
(\mathrm{m} / \mathrm{sec})\end{array}$ & $\begin{array}{c}\mathrm{V} \\
\text { eq.(10) } \\
(\mathrm{m} / \mathrm{sec})\end{array}$ & $\begin{array}{c}\mathrm{V} \text { eq. } \\
(8) / \mathrm{V}\end{array}$ \\
\hline SG $(10)$
\end{tabular}

8.3. Equations of Punching Shear Strength Capacity for Concrete Members Reinforced by GFRP Bar and Strengthened with Carbon Sheet

The punching capabilities of the slabs estimated Using two current codes (CSA S-806-12 and ACI 440.1R15) for FRP bars: 
8.3.1. ACI440.1R-15 (Guide for Designing and Constructing the Structural Concrete Reinforced with the FRP, 2015) [20]

The shear capability of FRP reinforced concrete slabs poorly documented in literature and building standards. Some construction codes provide the formulas below:

$V c=\frac{4}{5} \sqrt{f c^{\prime}} b_{o} k d$

$K=\sqrt{2 \rho_{f} n_{f}+\left(\rho_{f} n_{f}\right)^{2}}-\rho_{f} n_{f}$

$n_{f}=\frac{E_{f}}{E_{c}}$

$\mathrm{b}_{\mathrm{o}}=$ represents the control perimeter.

To adopt the code equations to calculate punching shear capacity for the slabs strengthened with FRP sheets, among the design of the effective depth and reinforcement ratio need adjusted to reflect the effect of the attached sheets on the punching shear capacity as follows:

$d_{e q}=\frac{A_{s f} E_{s f} H+A_{f} E_{f} d}{A_{s f} E_{s f}+A_{f} E_{f}}$

$\rho_{e q}=\rho_{f}+\rho_{s f} \frac{E s f}{E f}$

$A_{s f}, A_{f}=$ area of carbon sheet and GFRP bar respectively.

$E_{s f}, E_{F}=$ Modules of elasticity of carbon sheet and GFRP bar respectively.

$\mathrm{H}=$ thickness of slab.

$\rho_{e q}=$ Equivalent reinforcement ratio of carbon sheet and GFRP bars.

$\rho_{f}=$ Reinforcement ratio of GFRP bar

$\rho_{f s f}=$ reinforcement ratio of carbonsheet

\subsubsection{CSA S806-12 (Canadian Building Code) [21]}

The smallest of the three equations below should close as static punching shear strength in the Canadian building code.

$$
\begin{aligned}
& V c=0.028 \lambda \emptyset_{c}\left(1+\frac{2}{B c}\right)\left(E_{f} \rho_{f} f c^{\prime}\right)^{1 / 3} b_{\mathrm{o}} d \\
& V c=0.147 \lambda \emptyset_{c} q\left(E_{f} \rho_{f} f c^{\prime}\right)^{1 / 3} b_{\mathrm{o}} d \\
& V c=0.056 \lambda \emptyset_{c}\left(E_{f} \rho_{f} f c^{\prime}\right)^{1 / 3} b_{\mathrm{o}} d
\end{aligned}
$$

Where:

$q=\left(\frac{\propto s d}{b_{\mathrm{o}}}+0.19\right)$

$\mathrm{d}_{\mathrm{eq}}=$ the slab's equivalent depth.

$\mathrm{b}_{\mathrm{o}}=$ the control perimeter.

$f c^{\prime}=$ the concrete's compressive strength $(\mathrm{MPa})$.

$\beta=$ long/short span ratio, reaction area or concentrated load.

$\emptyset_{c}=$ the concrete's resistance factor taken as (1.0).

$\lambda=$ the factor of the modification which reflects the decreased mechanical characteristics of the lightweight concrete, is set as (1.0) for normal strength concrete.

$\lambda_{\mathrm{s}}=$ size effect modification factor. $\propto$ s equals 30 for the edge columns, 40 for interior columns and 20 for corner ones.

$f c u=$ the concrete's cube strength $(\mathrm{MPa})$.

$\mathrm{k}=$ the factor representing size.

\subsubsection{Code Recommendations}

The validity of the result of punching shear capacity with the traditional predication code requirements briefly discussed in Table 8 . In addition to the static punching shear tests, all dynamic impact tests based on the results of the static punching shear tests. Furthermore, the dynamic to estimated punching shear ratio ranges from (4.55-7.64) according to ACI 440.1R-15, whereas the values of the punching shear capacity that have been estimated on the basis of the above-mentioned codes and according to CSA S806-12, the ratio ranges from 4 to 5.12. According to the impact test results, punching failures occurred at a greater stress level than the projected punching shear capability. In addition, when compared to the CSA. 
S806-12 code the ratio of impact against static load based on ACI 4401R-15 typically varies between greater ranges. The dynamic to static punching shear ratio based on ACI 4401R-15 is almost higher than the CSA S806-12 code. Table8. Show a slight increase in the static punching shear for specimens with the same compressive strength of about (20-15.84) percentage according to ACI440.1R and CSA S806 codes, due to an increase in the reinforcement ratio. On other hand, when compared specimens $\mathrm{SGC}_{3}-\mathrm{B}_{2}, \mathrm{SGC}_{5}-\mathrm{B}_{1}$ with $\mathrm{SGC}_{4}-\mathrm{B}_{1}$, there was a decrease in the static punching shear of about (16.3) percentage because the slab reinforcement ratio decreased from (1.32to 1.1135) percentage despite the same compressive strength, while $\mathrm{SGC}_{4}-\mathrm{B}_{1}$ closed to $\mathrm{SGC}_{2}-\mathrm{B}_{1}, \quad \mathrm{SGC}_{1}-\mathrm{B}_{1}$. That means the reinforcement ratio is the control parameter. When the comparison between dynamic shear capacity (P impact) and code predicted (P estimated) according to ACI440.1 R and CSA S-806, punching-shear capacity ratio based on ACI 4401R-15 is almost higher than the CSA S806-12 code.
Table 8 shows a slight increase in the static punching shear for specimens with the same compressive strength of about (20-15.84) percentage according to ACI440.1R and CSA S806 codes, due to an increase in the reinforcement ratio. On other hand, when compared specimens $\mathrm{SGC}_{3}-\mathrm{B}_{2}, \mathrm{SGC}_{5}-\mathrm{B}_{1}$ with $\mathrm{SGC}_{4}-\mathrm{B}_{1}$, there was a decrease in the static punching shear of about (16.3) percentage because the slab reinforcement ratio decreased from (1.32to 1.1135) percentage despite the same compressive strength, while $\mathrm{SGC}_{4}-\mathrm{B}_{1}$ closed to $\mathrm{SGC}_{2}-\mathrm{B}_{1}$, $\mathrm{SGC}_{1}-\mathrm{B}_{1}$. That means the reinforcement ratio is the control parameter. When the comparison between dynamic shear capacity (P impact) and code predicted (P estimated) according to ACI440.1 R and CSA S-806, punching-shear capacity for the slabs which have been reinforced by the GFRP bars. The founded CSAS-806-12 equation has resulted in the punching shear Capacity GFRP bars safe predictions.

Table 8. Comparison of test results (impact force) with predictions of code

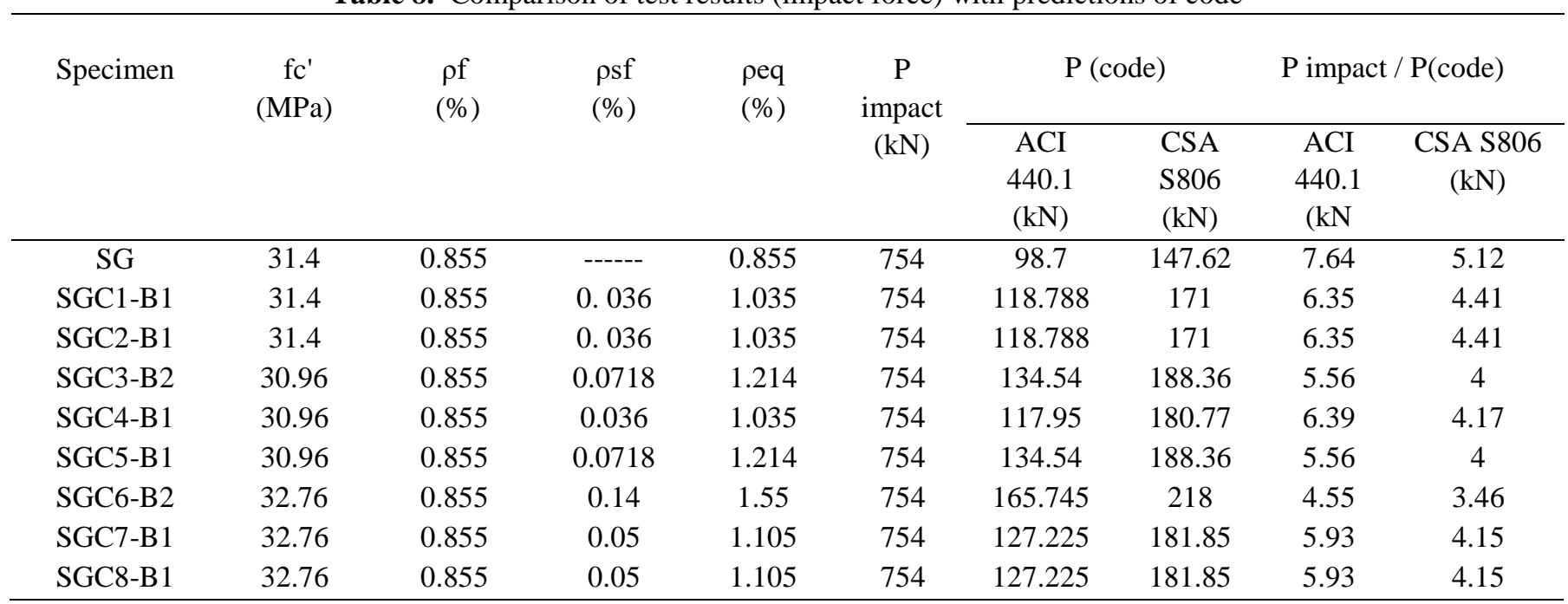




\section{Conclusions}

The experimental results and numerical investigation show the following conclusions, which summarized as follows:

- The increased layer of carbon sheet raises the shear punching capacity and improves the dynamic behavior of the structure.

- The carbon strip with less width and more numbers increases the shear punching capacity. It is better than a wide strip with fewer numbers.

- The increase in the area of carbon sheet ranging from (0.25 to 1$) \mathrm{m}^{2} \mathrm{SGC}_{4}-\mathrm{B}_{1}$ and $\mathrm{SGC}_{5}-\mathrm{B}_{1}$ led to a displacement reduction of $9.3 \%$.

- Increase CFRP sheet layer at the bottom of the slab from one layer to two layers leads to peak displacement reduction of $12 \%$.

\section{Abbreviations}

Ec. Elastic modulus of concrete

Ef Elastic modulus of GFRP

Esf Elastic modulus of carbon sheet

$f c^{\prime} \quad$ Compressive Strength of cylinder

$\mathrm{fcu} \quad$ Concrete cubic compressive strength

$f_{f u}$ Ultimate strength of GFRP

$f_{s u} \quad$ Ultimate strength of carbon sheet

$f t \quad$ Splitting Tensile Strength

g Acceleration due to gravity

$\mathrm{H} \quad$ Thickness of slab

K Factor accounting for the size effect.

M Dropping mass

$n_{f} \quad$ Ratio the elastic modulus of GFRP to

$n_{f} \quad$ the elastic modulus of concrete

of Flexural reinforcement ratio

$\rho b \quad$ Balance reinforcement ratio

psf Reinforcement ratio of carbon sheet

peq equivalent reinforcement ratio

d effective depth

deq equivalent depth

$r \quad$ Percentage reinforce ratio

S Spacing between reinforcement bars
$\mathrm{Vu} \quad$ ultimate shear strength

$\mathrm{Vp} \quad$ Critical velocity of perforation

w Density of material

efu Rupture strain of GFRP tensile reinforcement.

\section{Conflict of Interest}

The authors confirm that the current paper's publication does not result in a conflict of interest.

\section{References}

1. Li, Q. M., S. R. Reid, A.M. Ahmad-Zaidi. (2006)."Critical impact energies for scabbing and perforation of concrete target." Nuclear Engineering and design 236, no. 11; 1140-1148.

2. Daudeville, Laurent, Yann Malécot. (2011)."Concrete structures under impact." European Journal of Environmental and Civil Engineering 15, no. sup: 101-140.

3. Kennedy, R. P. (1976)."A review of procedures for the analysis and design of concrete structures to resist missile impact effects." Nuclear Engineering and Design, Vol.37, PP.183-203.

4. Alkloub, Amer Abdel Karim. (2015). "Behavior of reinforced concrete panels subject to impact by non-deformable projectiles."

5. Rahman, Ismail Abdul, Ahmad Mujahid Ahmad Zaidi, QadirBux, Imran Latif. (2010)."Review on empirical studies of local impact effects of hard missile on concrete structures." International Journal of Sustainable Construction Engineering and Technology 1, no. 1: 73-98.

6. Army Corps of Engineers, ACE. (1946). "Fundamentals of protective structures", Report AT120 AT1207821, Office of the Chief of Engineers.

7. National Defense Research Committee, NDRC. (1946)."Effects of impact and explosion" Summary Technical Report of Division 2, vol. 1, Washington, and DC. 
8. Comite euro-international du beton, plenary session. (1988). Concrete structures under impact and impulsive loading: Synthesis report. Comite euro-international du beton.

9. Fullard, Kenneth, M. R. Baum, P. Barr. (1991)."The assessment of impact on nuclear power plant structures in the United Kingdom." Nuclear engineering and Design 130, no. 2: 113-120.

10. Laurent D., Yann M. (2011). "Concrete structures under impact", Joseph Fourier University - Grenoble, 328 PP.

11. Berriaud C., Dulac J., Perrot J., AvetFlancard R. (1983). "Impact on concrete: Synthesis of French Studies." Proc.7th SMiRT, Chicago, USA, no J8/2.

12. Murtiadi, Surwayan, H. Marzouk. (2001)."Behavior of high-strength concrete plates under impact loading." Magazine of Concrete Research 53, no. 1: 43-50.

13. Buzaud, Eric, Ch Cazaubon, Daniele Chauvel. (2007)."Assessment of empirical formulae for local response of concrete structures to hard projectile impact." Concrete under severe conditions, Environment, loading.

14. Nguyen-Minh, Long,Marián Rovňák. "Punching shear resistance of interior GFRP reinforced slab-column connections." Journal of Composites for Construction 17, no. 1 (2013): 2-13.

15. El-Ghandour Abdel Wahab, Kypros Pilakoutas, Peter Waldron. (2003). "Punching shear behavior of fiber reinforced polymers reinforced concrete flat slabs: experimental study." Journal of Composites for Construction 7, no. 3: 258265.

16. Esfahani, Mohammad Reza, M. Reza Kianoush, and A. R. Moradi.(2009). "Punching shear strength of interior slabcolumn connections strengthened with carbon fiber reinforced polymer sheets." Engineering Structures 31, no. 7: 1535-1542.

17. Metwally, Ibrahim M. (2013). "Prediction of punching shear capacities of two-way concrete slabs reinforced with FRP bars." HBRC Journal 9, no. 2 : 125-133.

18. Jae-Ick Jang, Su-Min Kan,(2019). "Punching Shear Behavior of Shear Reinforced Slab-Column Connection with Varying Flexural Reinforcement "International volume 13, article 29.

19. Mink wan Ju 1, Kyoung soo Park 1 and Cheolwoo Park, (2018). "Punching Shear Behavior of Two-Way Concrete Slabs Reinforced with Glass-Fiber-Reinforced Polymer (GFRP) Bars." journal of polymer.

20. ACI, (2015)."Guide for the design and construction of structural concrete reinforced with FRP bars (ACI 440.1 R15)." American Concrete Institute.

21. Standard, C. S. A. (2012)."Design and Construction of Building Structures with Fiber -Reinforced Polymers (CSA S806S12)." Canadian Standards Association, Mississauga, Canada. 